\title{
Correction to: Influence of explant types, non-embryogenic synseed and reduced oxygen environment on in vitro conservation of Bacopa monnieri (L.) Wettst
}

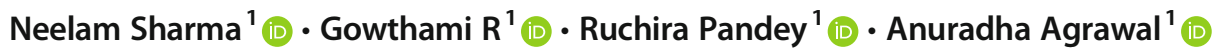 \\ Published online: 3 July 2020 \\ (C) The Society for In Vitro Biology 2020
}

\section{Correction to: In Vitro Cellular \& Developmental Biology - Plant https://doi.org/10.1007/s11627-020-10078-9}

Readers should note the following error in the original version of this article:

The sentence that now correctly reads "However, some accessions (including IC468878 used in the present study) have a short conservation period and require to be subcultured every 1-2 mo." instead read "However, some accessions (including IC468878 used in the present study) have a short conservation period and require to be subcultured every 6 mo."

The original article has been corrected.

The online version of the original article can be found at https://doi.org/ 10.1007/s11627-020-10078-9

Neelam Sharma

neelam.sharma1@icar.gov.in; sharma.neel.59@gmail.com

Gowthami R

gowthami.r@icar.gov.in

Ruchira Pandey

ruchira.pandey@icar.gov.in

Anuradha Agrawal

anuradha.agrawal@icar.gov.in

1 Tissue Culture and Cryopreservation Unit, National Bureau of Plant Genetic Resources, Pusa Campus, 110012, New Delhi, India 